\title{
Dromedary milk fat: thermal and structural properties 1. Crystalline forms obtained by slow cooling
}

\author{
Nadia KARRAY ${ }^{\mathrm{a}}$, Christelle LOPEZ ${ }^{\mathrm{b}}$, Pierre LESIEUR ${ }^{\mathrm{c}, \mathrm{d}}$, Michel OLLIVON $^{\mathrm{e} *}$ \\ a Unité d'analyse alimentaire, ENIS, BPW 3038 Sfax, Tunisie \\ b UMR Science et Technologie du Lait et de l'Oeuf, INRA-Agrocampus, \\ 65 rue de Saint-Brieuc, 35042 Rennes Cedex, France \\ c LURE, Université Paris-Sud, Bâtiment 209D, 91405 Orsay Cedex, France \\ d UMR Physico-Chimie des Colloïdes, Université Henri Poincaré, BP 239, \\ 54506 Vandœuvre-lès-Nancy, France \\ e UMR 8612 du CNRS, Équipe Physico-Chimie des Systèmes Polyphasés, 5 rue J.B. Clément, \\ 92296 Châtenay-Malabry, France
}

Received 12 February 2004 - Accepted 2 April 2004

Published online 7 June 2004

\begin{abstract}
The thermal and structural behavior of anhydrous dromedary milk fat (ADMF) was studied by a technique that allowed simultaneous time-resolved synchrotron X-ray diffraction as a function of temperature (XRDT) and high sensitivity differential scanning calorimetry (DSC). As the camel probably represents the mammalian species best adapted to the hottest temperatures on earth as well as to harsh climatic conditions, the fatty acid composition of ADMF and its thermal properties are of special interest. In this paper, the first of a series, the crystalline organizations made by the triacylglycerols (TG) of ADMF during a slow cooling rate at $\mathrm{dTT} / \mathrm{dt} \mid=0.1^{\circ} \mathrm{C} \cdot \mathrm{min}^{-1}$ are addressed. The crystalline form obtained from about $29.5{ }^{\circ} \mathrm{C}$ corresponds to a lamellar structure with a double-chain length longitudinal organization of the TG molecules $(2 \mathrm{~L}=42.3 \AA)$ associated with a $\beta$ ' lateral packing of the chains. The crystallization range which spreads over about $75-80^{\circ} \mathrm{C}$, is similar to that observed for bovine milk fat, although the final melting temperature is higher by about $5-8{ }^{\circ} \mathrm{C}$. DSC scans revealed the existence of up to 6 exotherms on slow cooling. A similar complex behavior was also observed on heating. PEAKFIT analysis of the XRDT individual patterns and their evolutions observed at small angles also showed the existence of additional molecular packings. However, XRDT analysis was unable to resolve individual structures. A possible epitaxy phenomenon during crystallization is discussed.
\end{abstract}

Polymorphism / X-ray diffraction / differential scanning calorimetry / solid fat content / epitaxy

Résumé - Propriétés thermiques et structurales de la matière grasse de lait de dromadaire. 1. Formes cristallines obtenues lors d'un refroidissement lent. Les propriétés thermiques et structurales de la matière grasse anhydre extraite du lait de dromadaire (ADMF) ont été étudiées par une nouvelle technique qui permet des mesures simultanées, sur un même échantillon, des signaux de microcalorimétrie différentielle à balayage (DSC) et de diffraction des rayons X en fonction du temps et de la température. L'étude des propriétés thermiques de la matière grasse du lait de chamelle, en relation avec sa composition, revêt un intérêt particulier si l'on considère les conditions

\footnotetext{
* Corresponding author: michel.ollivon@ @ep.u-psud.fr
} 
extrêmes de température auxquelles ce mammifère est adapté. Cet article, qui est le premier d'une série, est consacré à l'étude des organisations cristallines formées par les triacylglycérols (TG) de l'ADMF lors d'un refroidissement à $0,1^{\circ} \mathrm{C} \cdot \mathrm{min}^{-1}$. Les formes cristallines obtenues à partir de $29,5^{\circ} \mathrm{C}$ correspondent à une structure lamellaire à deux longueurs de chaînes $(2 \mathrm{~L}=42,3 \AA)$ et à un empilement latéral des chaînes d'acides gras de type $\beta$ '. La plage de cristallisation couvre un domaine d'environ $75-80^{\circ} \mathrm{C}$, similaire à celui observé pour la matière grasse laitière bovine, bien que la température finale de fusion soit plus élevée pour le dromadaire d'environ 5 à $8{ }^{\circ} \mathrm{C}$. Les enregistrements de DSC observés à la cristallisation comme à la fusion révèlent l'existence d'environ 6 évènements thermiques qui contrastent avec l'apparente simplicité du comportement structural. Une analyse fine des pics de diffraction des rayons $\mathrm{X}$ et de leurs évolutions a aussi montré l'existence d'autres empilements longitudinaux mais sans pouvoir différencier ces structures de manière univoque. Une croissance cristalline de type épitaxie est proposée pour expliquer ce comportement structural.

Polymorphisme / diffraction des rayons $\mathrm{X} /$ microcalorimétrie différentielle à balayage / teneur en solide / épitaxie

\section{INTRODUCTION}

The camel population in the world is estimated at several million animals. The dromedary rearing area is situated in the tropical and subtropical arid as well as semi-arid regions of Africa and Asia. There are two different species of camels belonging to the genus camelus, namely, the Dromedary Camel (Camelus dromedarius; one-humped) and Bactrian Camel (Camelus Bactrianus; two-humped). Camels in Africa and the Near East are Dromedaries while those in Asia are Bactrians. The camel is the most efficient domestic animal for converting vegetable matter into work, milk and meat in hot arid areas. The chief role of the camel relates directly to its remarkable adaptation to extremely harsh conditions. This ability is the result of several anatomical and physiological characteristics.

Camel milk is already used for human consumption. Most of the camel milk is drunk fresh, when it has just turned sour or is consumed as a pasteurized milk in some cities [26]. Camel milk is also consumed as butter, but only rarely as cheese.

Several studies have been carried out to determine the general composition of the milk $[4,12,33]$ and its ability to transform into dairy products $[2,6,26,27]$.
The anhydrous dromedary milk fat (ADMF), which is the fat isolated from butter, is an essential nutriment. However, data about the composition and physical properties of dromedary milk fat are still scarce.

In camel milk, fat, that represents about $3.6 \%$ of the composition [33], is dispersed in the form of globules, enveloped in a membrane [3], derived from the secreting cell and constituted by phospholipid-protein complexes. Milk fat is mainly composed by triacylglycerols (TG) with a broad variety of FA composition. The complexity of its composition originates from the extreme diversity of its FA with respect to chain lengths, position and number of double bonds and branching.

FA composition of camel milk fat varies as a function of the countries where camels live $[1,6,30,33]$. FA composition is influenced by environmental and physiological factors such as diet, stage of lactation and genetic differences within the species [6] (Tab. I).

Various authors have determined the FA composition of camel milk fat and compared it with that of bovine milk fat. Shortchain FA (C4-C12) are present in very small amounts in camel milk fat compared with bovine milk fat $[1,3,6]$.

Depending on the author and the likely geographic area considered, the long-chain 
Table I. Fatty acid compositions (mole \%) of dromedary and bovine milk fats.

\begin{tabular}{|c|c|c|c|c|c|}
\hline \multirow{2}{*}{$\begin{array}{l}\text { Fatty acid } \\
\text { Carbon number: } \\
\text { unsaturat. position }\end{array}$} & \multicolumn{4}{|c|}{ Dromedary $(\%)$} & \multirow{2}{*}{$\begin{array}{c}\text { Bovine (\%) } \\
\text { (d) }\end{array}$} \\
\hline & (a) & (b) & (c) & (d) & \\
\hline $\mathrm{C} 4: 0$ & 0.1 & - & 1.10 & 0.60 & 2.6 \\
\hline C6:0 & 0.2 & - & 0.20 & 0.22 & 1.65 \\
\hline C8:0 & 0.2 & 0.1 & 1.10 & 0.21 & 1.12 \\
\hline C10:0 & 0.2 & 0.12 & 0.20 & 0.25 & 2.75 \\
\hline $\mathrm{C} 12: 0$ & 0.9 & 0.77 & 0.80 & 1.19 & 3.89 \\
\hline C14:0 & 11.4 & 10.14 & 9.70 & 13.11 & 13.05 \\
\hline $\mathrm{C} 14: 1 \omega 5$ & 1.6 & 1.86 & 0.80 & 0.70 & 1.7 \\
\hline C15:0 & 1.7 & 1.62 & 1.98 & 0.10 & 1.5 \\
\hline $\mathrm{C} 16: 0$ & 26.7 & 26.60 & 28.50 & 31.45 & 38.59 \\
\hline $\mathrm{C} 16: 1 \omega 7$ & 11.0 & 10.40 & 7.20 & 11.62 & 2.3 \\
\hline $\mathrm{C} 17: 0$ & - & 1.21 & 1.10 & - & - \\
\hline $\mathrm{C} 18: 0$ & 11.1 & 12.20 & 14.90 & 16.12 & 8.65 \\
\hline 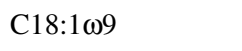 & 25.5 & 26.25 & 24.60 & 20.70 & 20.52 \\
\hline $\mathrm{C} 18: 2 \omega 6$ & 3.6 & 2.94 & 4.40 & 1.19 & 1.92 \\
\hline $\mathrm{C} 18: 3 \omega 3$ & 3.5 & 1.37 & 1.38 & 1.33 & 1.34 \\
\hline C19:0 & - & 0.57 & - & - & - \\
\hline C20:0 & 0.6 & 0.57 & 1.38 & 0.49 & 0.49 \\
\hline $\mathrm{C} 21: 0$ & - & 0.38 & - & - & - \\
\hline $\mathrm{C} 22: 0$ & - & 0.08 & - & - & - \\
\hline $\mathrm{C} 22: 1$ & - & 0.57 & - & - & - \\
\hline Total * & 98.3 & 97.75 & 99.34 & 99.28 & 102.07 \\
\hline $\mathrm{C} 4-\mathrm{C} 12$ & 1.6 & 0.99 & 3.40 & 2.47 & 12.01 \\
\hline Uns./Sat. & 0.85 & 0.80 & 0.63 & 0.56 & 0.37 \\
\hline $\begin{array}{l}\text { Mean chain length } \\
\text { of even saturated } \\
\text { FA } n C \geq 12\end{array}$ & & & & 16.05 & 15.65 \\
\hline
\end{tabular}

(a) from [33]; (b) from [1]; (c) from [6]; and (d) from [3].

* Data are reported as found in the literature.

saturated FA, of even number (C14-C22) and odd number (C15-C23) are higher for camel milk fat than those for bovine milk fat $[1,33]$. Stearic acid (C18:0) is present at a higher amount in camel milk fat $[1,3]$. The comparison of the amount of palmitic acid (C16:0) in camel and bovine milk fat is further discussed by the authors. AbuLehia [1] found that it is present in similar amounts in camel and bovine milk fat.
However, Attia et al. [3] found that the proportion of C16:0 was lower in dromedary milk fat and Farah et al. [6] found that this FA was present in higher quantities in camel milk originating from Kenya.

The content of unsaturated (C14-C18) FA is significantly higher in camel milk fat than in bovine milk fat. The unsaturated FA of camel milk fat are characterized by a higher amount of the C16:1 FA as compared with 
bovine milk fat. It was found that oleic acid (C18:1), the most abundant unsaturated $\mathrm{FA}$, is present at a higher amount in camel milk fat [1], or that the proportion is practically the same in dromedary and bovine milk fat [3].

The second source of complexity of milk fat properties originates from its complex polymorphism. As observed for most lipids, each TG of ADMF can exhibit several crystalline forms. The existence of a polymorphism for each TG was studied by several authors $[9,29,34]$. This polymorphism being mainly monotropic, rapidly-crystallized forms are metastable and the transitions between metastable and stable forms are irreversible. The occurrence of the different crystalline forms strongly depends on the thermal history of the TG. Each polymorphic form being characterized by its own melting point, the melting behavior of ADMF is expected to be complex in relation to its composition. The technological applications and textural properties of creams and ADMF-rich products will strongly depend on the thermal and structural properties as well as on their TG compositions. Understanding of the functionality of ADMF in food products necessitates the knowledge of its physical properties. As observed for other fats, X-ray diffraction (XRD) and differential scanning calorimetry (DSC) are the best techniques to characterize, respectively, the structural and thermal properties of ADMF [18-25, 32]. Extensive descriptions of TG polymorphism based on data obtained using these techniques can be found in the literature [9, 29].

Briefly, XRD is an essential tool to identify the crystalline structures and polymorphism of pure TG and complex fats. Polymorphism results from the different possibilities of lateral packing of the FA chains and longitudinal stacking of molecules in lamellae. These two levels of organization are identifiable from the short and long spacings observed by XRD at wide and small angles, respectively, as detailed by Lopez et al. [19].
The lateral packings of TG molecules frequently observed are $\alpha, \beta$, and $\beta$ in the order of their increasing stability. They have been related to different subcells that have been described in detail [14]. The longitudinal stackings of TG molecules correspond commonly to double or triple chain lengths ( $2 \mathrm{~L}$ or $3 \mathrm{~L})$. The long spacings, measured by XRD at small angles, correspond to the repeat distance in the direction perpendicular to the lamellae.

DSC permits characterization of the thermal properties of pure TG and fats. The consequence of the complex TG composition of fats is that they do not have a true melting point but a broad melting range. The complex DSC recordings result from both the broad distribution of TG composition and the polymorphism of monotropic type of the TG [9]. The DSC recordings depend strongly on heating or cooling rates and on the entire thermal history of the sample [28].

ADMF has a broad melting range and the thermograms present more melting peaks than bovine ones, which is consistent with the differences in their FA compositions [3, 31]. The final melting temperature and the thermal enthalpy are higher in dromedary milk fat, due to the very hot climate in which dromedaries live. Melting of the camel milk fat starts around $-26{ }^{\circ} \mathrm{C}$ and is complete at about $43{ }^{\circ} \mathrm{C}$ [31]. Attia et al. [3] found that final melting occurs at about $44{ }^{\circ} \mathrm{C}$ vs. $39^{\circ} \mathrm{C}$ for that of bovine milk fat. These characteristics are consistent with the relatively high concentration of long-chain FA that represent an important fraction of high melting point TG and a lower percentage of TG that melt in the medium range around $15^{\circ} \mathrm{C}$ [31].

XRD complements DSC for elucidating polymorphism of pure TG and fats. The coupling of XRD as a function of temperature (XRDT) and DSC was used to characterize the structural and thermal behaviors of pure TG $[10,16]$, fats $[15,17,19,21-23,25$, 32] and dispersed systems such as natural bovine milk fat globules [18, 20, 23, 24]. 
Coupling of DSC and XRDT is applied here to characterizing the very specific thermal and structural properties of ADMF. In this paper, the first of a series, we examined the crystalline structures formed by TG during slow cooling of ADMF and their evolution as a function of temperature during a subsequent heating.

\section{MATERIALS AND METHODS}

\subsection{Samples}

Dromedary milk was obtained from an eighteen-camel herd (Camelus dromedaries) (magharbi breed) belonging to the Arid Region Institute (Medenine, Tunisia).

Cream was obtained from the camel milk after centrifugation three times at $25^{\circ} \mathrm{C}$ and $3000 \times g$ for 20 min on a Jouan GR 20,22 apparatus (Jouan, Saint Herblain, France).

Anhydrous Dromedary Milk Fat (ADMF) was extracted from the cream using the following procedure: first, after manual churning of the cream (at $\mathrm{T}=12-15^{\circ} \mathrm{C}$ ), $10 \mathrm{~g}$ of butter were melted to $60^{\circ} \mathrm{C}$ and centrifuged for $2 \mathrm{~min}$ at $3000 \times \mathrm{g}$. The upper organic phase was separated and filtered at $50{ }^{\circ} \mathrm{C}$ in the presence of sodium anhydrous $\left(\mathrm{Na}_{2} \mathrm{SO}_{4}\right)$ on a filter of glass wool. The dried and filtered fraction constitutes the ADMF.

\subsection{DSC measurements}

Thermal analysis was recorded by differential scanning calorimetry (DSC) using a DSC-7 (Perkin Elmer, St-Quentin-enYvelines, France) equipped with Intracooler II and running under Pyris Software. Analyses were recorded in triplicate. Samples of ADMF were loaded in aluminum pans of $50 \mu \mathrm{L}$ (pan, part \#B014-3021 and cover, part \#B014-3004) that were hermetically sealed. An empty, hermetically sealed aluminum pan was used as reference. Calibration was done with lauric acid (m.p. $\left.43.7^{\circ} \mathrm{C}, \Delta \mathrm{Hm}=35.7 \mathrm{~kJ} \cdot \mathrm{mol}^{-1}\right)[8]$.

\subsection{XRDT/DSC measurements}

The coupled X-ray diffraction as a function of temperature (XRDT) recorded at both small and wide angles and high-sensitivity differential scanning calorimetry (DSC) setup was installed on the D22 bench of the DCI synchrotron of LURE (Laboratoire pour l'Utilisation du Rayonnement Électromagnétique, Orsay, France). This setup has already been described $[11,19]$. Briefly, two linear detectors allow the recording of simultaneous small- $(\mathrm{q}=0$ $\left.0.45 \AA^{-1}\right)$ and wide- $\left(\mathrm{q}=1.1-2.1 \AA^{-1}\right)$ angle XRD with sample-to-detector distances of 177 and $30 \mathrm{~cm}$, respectively. Both XRDT data and DSC signals are simultaneously collected from the same sample with a single computer in order to avoid any time or temperature shift in the data collection. The channels of the detectors are calibrated to express the XRDT data in the scattering vector $\mathrm{q}$ with $\mathrm{q}=4 \pi \cdot \sin (\theta) / \lambda=2 \pi / \mathrm{d} ; \mathrm{q}$ in angstrom $^{-1}, \theta$ in degrees is the angle of incidence of the $\mathrm{X}$-ray wavelength, $\mathrm{d}$ in angstrom is the repetition distance between two planes. The calibration of the detectors was carried out at wide angles with high purity tristearin, which is characterized by short spacing of $4.59,3.85$ and $3.70 \pm 0.01 \AA$ at room temperature [29], complemented at small angles with silver behenate characterized with a long spacing of $58.380 \pm 0.001 \AA$ [5], as previously described [19].

The calorimeter coupled to X-ray diffraction was calibrated with lauric acid [11]. The samples of ADMF to be analyzed by coupled XRDT and DSC techniques were loaded into thin glass Lindeman capillaries (GLAS Muller, Berlin, Germany) as previously described [24]. The crystallization behavior of AMF was conducted on cooling at $|\mathrm{dT} / \mathrm{dt}|=0.1^{\circ} \mathrm{C} \cdot \mathrm{min}^{-1}$. The melting behavior was monitored by heating of the samples at $\mathrm{dT} / \mathrm{dt}=1{ }^{\circ} \mathrm{C} \cdot \mathrm{min}^{-1}$.

Each XRD pattern recorded as a function of temperature simultaneously at small and wide angles was analyzed using PEAKFIT software (Jandel Scientific, Erkarth, Germany) to determine the position, the maximal 

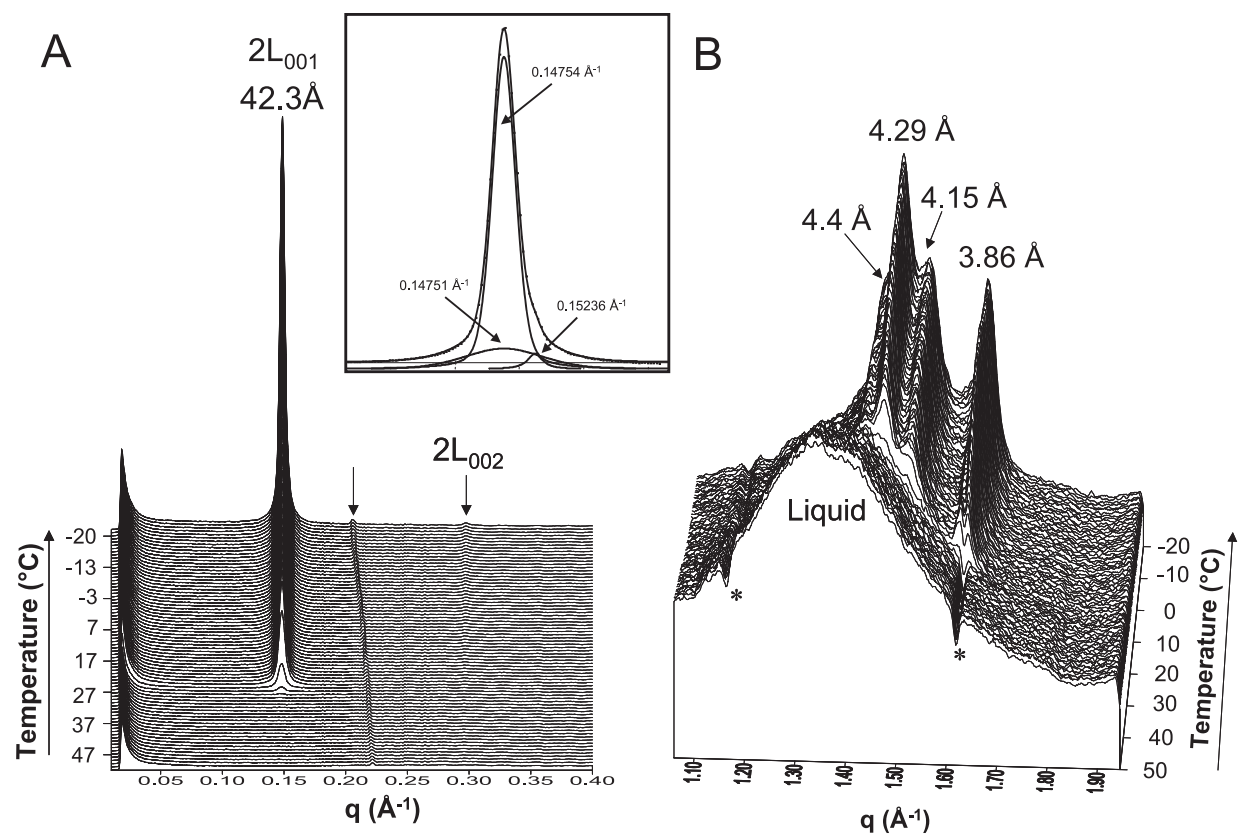

Figure 1. Three-dimensional plots of small- (A) and wide- (B) angle X-ray diffraction patterns recorded as a function of time during cooling of anhydrous dromedary milk fat at $0.1^{\circ} \mathrm{C} \cdot \mathrm{min}^{-1} \mathrm{using}$ coupled XRDT-DSC. Insert: alternative PEAKFIT analysis of the long spacings of the last pattern observed after cooling completion. (Asterisk symbols correspond to negative peaks due to the wide-angle detector defects).

intensity of the peaks and the middle-height width of the peak recorded at small angles. The diffraction peaks wee fitted with the Gaussian-Lorentzian sum (amplitude) equation as previously described [20].

\section{RESULTS}

\subsection{Crystalline forms obtained by slow cooling of ADMF}

Anhydrous Dromedary Milk Fat (ADMF) was very slowly cooled in the glass capillaries of the coupled XRDT/DSC apparatus, from 60 to $-20{ }^{\circ} \mathrm{C}$, with a cooling rate at $|\mathrm{dT} / \mathrm{dt}|=0.1{ }^{\circ} \mathrm{C} \cdot \mathrm{min}^{-1}$, to study the formation of the crystalline forms of TG. After crystallization, the sample was analyzed on heating at $\mathrm{dT} / \mathrm{dt}=1{ }^{\circ} \mathrm{C} \cdot \mathrm{min}^{-1}$ from -20 to $60{ }^{\circ} \mathrm{C}$.

\subsubsection{Structural analysis}

The plots of the XRD patterns, recorded as a function of time at both small and wide angles during cooling of ADMF, vs. temperature, are presented in Figure 1, as threedimensional plots.

The small-angle XRDT patterns show from about $\mathrm{T}=29-30{ }^{\circ} \mathrm{C}$ the progressive development of a single sharp line at about $\mathrm{q}=0.15 \AA^{-1}$, corresponding to crystallization of TG as a function of the decrease in temperature (Fig. 1A). The formation of this crystalline structure is attested by an increase in X-ray scattering at very small angles ( $\left.q \sim 0.03 \AA^{-1}\right)$. The small peak recorded at about $\mathrm{q}=0.2-0.225 \AA^{-1}$ from the beginning of the experiment at $\mathrm{T}=50^{\circ} \mathrm{C}$ is discussed elsewhere (see discussion).

The wide-angle XRD patterns simultaneously recorded as a function of temperature 


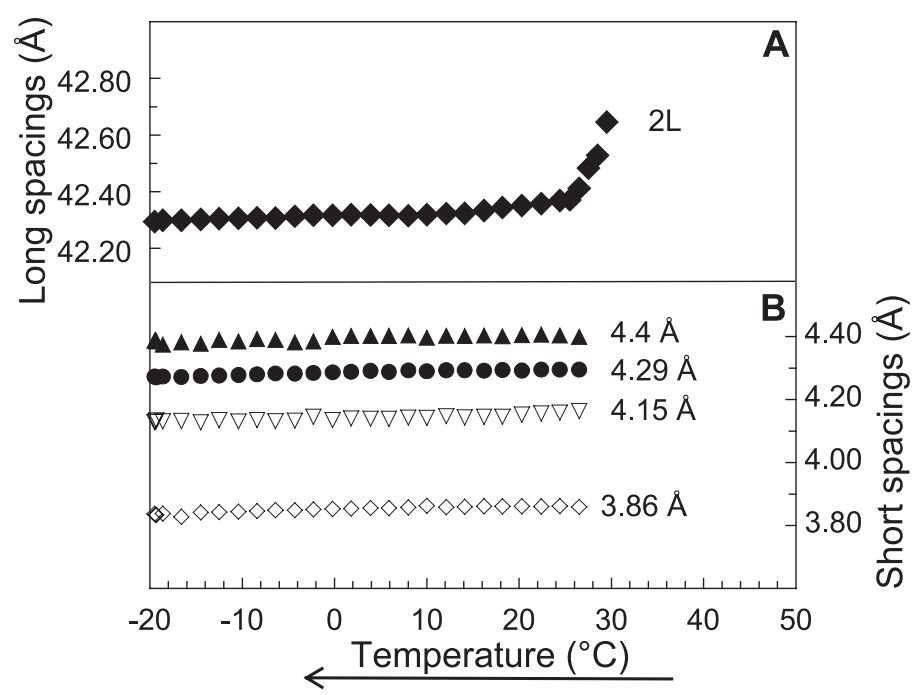

Figure 2. Evolution of the (A) long and (B) short spacings of anhydrous dromedary milk fat crystals shown in Figure 1 during cooling at $0.1^{\circ} \mathrm{C} \cdot \mathrm{min}^{-1}$.

(Fig. 1B) show in the 50 to $-20{ }^{\circ} \mathrm{C}$ range of temperature a broad peak which corresponds to scattering from liquid TG [13]. From about $27{ }^{\circ} \mathrm{C}$, four diffraction lines appear and progressively increase as a function of temperature.

The XRD patterns recorded both at small and wide angles as a function of temperature during cooling of $\mathrm{ADMF}$ at $\mathrm{dTT} / \mathrm{dt} \mid=$ $0.1^{\circ} \mathrm{C} \cdot \mathrm{min}^{-1}$ were analyzed using PEAKFIT Software in order to determine the position and the maximal intensity of each diffraction peak.

\subsubsection{Spacing evolution}

The evolutions vs. temperature of the long and short spacings calculated from the peaks of diffraction recorded, respectively, at small and wide angles (Figs. 1A and 1B), are shown in Figures 2A and 2B.

The sharp line characterized at small angles corresponds to the formation of a well-defined lamellar structure. The period of this structure corresponds to $42.65 \AA$ when it appears at about $30^{\circ} \mathrm{C}$. This thick- ness which corresponds, according to the literature, to a longitudinal organization of TG molecules with a two-length chain structure (2L) decreases significantly from $42.65 \AA\left(29.5^{\circ} \mathrm{C}\right)$ to $42.37 \AA\left(25.5^{\circ} \mathrm{C}\right)$ during cooling of ADMF (Fig. 2A). From $25^{\circ} \mathrm{C}$ to $-20{ }^{\circ} \mathrm{C}$, the thickness of the $2 \mathrm{~L}$ structure which is likely constituted by long-chain saturated FA further decreases to $42.28 \AA$ as the density increases as a function of temperature, in relation to dilatation. Then, TG with shorter FA chains and/or with a monounsaturated FA may crystallize. The progressive crystallization of TG as a function of the length of their FA chains likely induces the decrease in the thickness of the 2L lamellar structure formed in the 29.5-25.5 ${ }^{\circ} \mathrm{C}$ range of temperature. The lowintensity peak recorded at $\mathrm{q}=0.2974 \AA^{-1}(\mathrm{~d}=$ $21.13 \AA$, at $-20^{\circ} \mathrm{C}$ ) corresponds to the second order $\left(2 \mathrm{~L}_{002}\right)$ of the main line.

The broad peak recorded at wide angles from the beginning of the experiment at $50{ }^{\circ} \mathrm{C}$ to about $27^{\circ} \mathrm{C}$ is centered at about $\mathrm{q}=$ $1.38 \AA^{-1}$ (4.55 $\AA$ ) (Fig. 1B). This peak 
corresponds to scattering from the organization of TG molecules in their liquid state [13]. For $\mathrm{T}<27^{\circ} \mathrm{C}$, four diffraction peaks appear simultaneously at wide angles. They correspond to short spacings of $4.4 \AA, 4.29 \AA$, $4.15 \AA$ and $3.86 \AA$ (Figs. $1 \mathrm{~B}$ and $2 \mathrm{~B}$ ). From previous studies, we interpreted that they are related to the formation of at least two lateral organizations of the FA chains in a perpendicular orthorhombic packing, corresponding to subcells of $\beta$ ' type [23]. These two different lateral packings of the FA chains coexist during the slow cooling of ADMF.

The short spacings do not show a significant evolution during cooling (Fig. 2B). This means that no changes occur in the lateral packing of FA chains as a function of temperature.

\subsubsection{Intensity evolution}

The evolutions of maximal intensity of diffraction peaks recorded simultaneously at small and wide angles (Figs. 1A and 1B) during slow cooling of ADMF are presented in Figures $3 \mathrm{~A}$ and $\mathrm{BB}$ as a function of temperature.

At small angles, variations of the main line $(2 \mathrm{~L})(42.3 \AA)$ can be divided into three domains (Fig. 3A). The intensity strongly increases from its formation at about $30^{\circ} \mathrm{C}$ to $25.5{ }^{\circ} \mathrm{C}$ (slope $=6.26 \% /{ }^{\circ} \mathrm{C}$ ). This strong increase corresponds to fast crystallization and is related to the initial decrease in the lamellae thickness observed in the same range of temperature (Fig. 2A). The second domain of increase in intensity is situated between 25 and $6{ }^{\circ} \mathrm{C}\left(\right.$ slope $\left.=1.88 \% /{ }^{\circ} \mathrm{C}\right)$. Then, from $6{ }^{\circ} \mathrm{C}$ until the end of the cooling process at $-20^{\circ} \mathrm{C}$, the $2 \mathrm{~L}$ line still increases in intensity (slope $=1.46 \% /{ }^{\circ} \mathrm{C}$ ), meaning that the crystallization process is not yet finished at this temperature. This increase in intensity of the 2L line (Figs. 1A and 2A) means that all the TG of ADMF are not crystallized at $-20{ }^{\circ} \mathrm{C}$. As a consequence, we have to consider that the baseline of the DSC recording is not reached at the end of the experiment (see below).
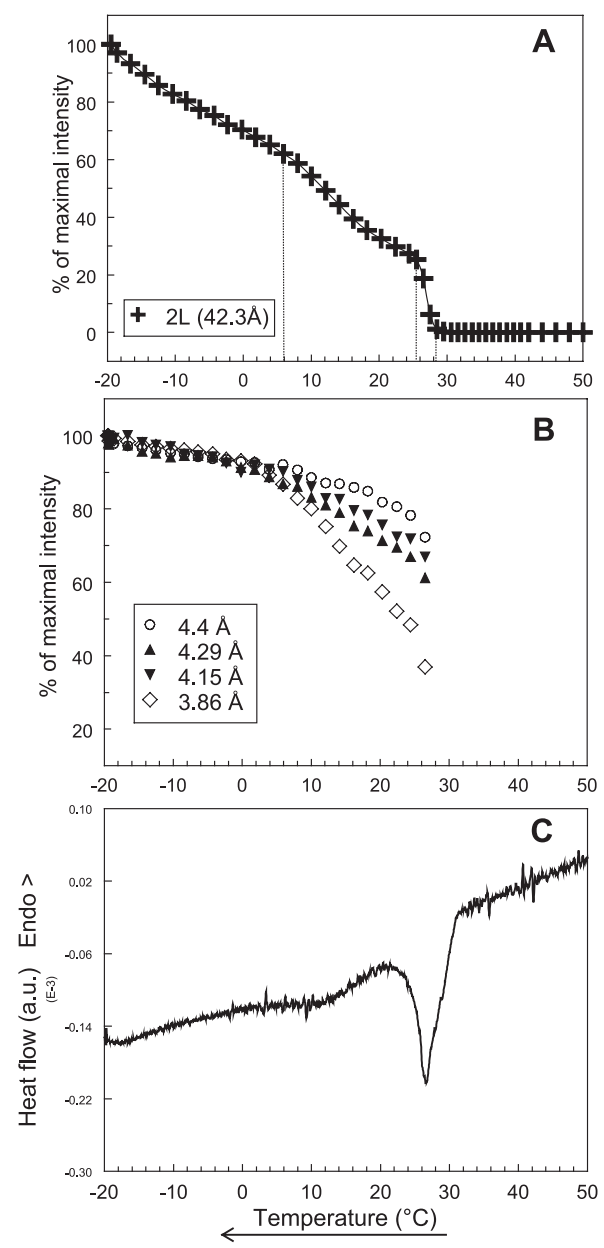

Figure 3. Evolution of the maximal intensities of the diffraction peaks recorded in Figure 1 (100\% corresponds to the strongest peak). (A) Evolution of the long spacings, (B) evolution of the short spacings, and (C) DSC crystallization curve recorded simultaneously during cooling of anhydrous dromedary milk fat at $0.1^{\circ} \mathrm{C} \cdot \mathrm{min}^{-}$.

At wide angles, the four diffraction peaks appear simultaneously and increase in intensity from their formation to $-20{ }^{\circ} \mathrm{C}$ (Fig. 3B). A parallel increase in intensity is observed for peaks corresponding to $\mathrm{SS}=$ $4.29 \AA$ and $4.15 \AA$, from $27^{\circ} \mathrm{C}$ until the end of the cooling (Fig. 3B). Contrary to previous XRDT analysis of bovine milk, it was 
not possible to clearly identify different $\beta$, phase behaviors from this plot [23].

From the comparison of intensity variations at both small and wide angles, we concluded that the longitudinal organization of TG, $2 \mathrm{~L}(42.3 \AA)$, is related to at least two lateral organizations of the acylglycerol chains of FA, of $\beta$ ' type, coexisting in the same lamellar structure.

\subsubsection{Small-angle XRD peak width evolution}

While an increase due to the coexistence of several organizations is expected, surprisingly, the peak width, measured at middle-height, of the single line recorded at small angles decreases as a function of temperature during slow cooling of ADMF (Fig. 5).

The middle-height width of a diffraction peak (PW, expressed in $\AA^{-1}$ ) recorded at small angles can be related to structural information on the organization of TG molecules into crystals [7]. The PW of the $2 \mathrm{~L}$ $(42.3 \AA)$ line decreases from about $0.006304 \AA^{-1}$ at $28{ }^{\circ} \mathrm{C}$ to $0.004646 \AA^{-1}$ at $-20{ }^{\circ} \mathrm{C}$.

This means either that the mean size of the $2 \mathrm{~L}(42.3 \AA)$ crystals increases during cooling or that the degree of organization of the TG is more important as a function of the decrease in temperature. Simplification of the Scherrer equation, taking into account XRD at very small angles, allows the approximation of the thickness of the crystals formed $[7,24]$. The equation is the following: $L=4 \pi / \Delta q$, where $L$ (expressed in $\AA$ ) is the thickness of the crystal, and $\Delta \mathrm{q}$ (expressed in $\AA^{-1}$ ) is the middle-height width of the diffraction peak observed. Thus, we estimated that the $2 \mathrm{~L}$ crystals are about $1990 \AA$ at $28^{\circ} \mathrm{C}$, whereas they are about $2700 \AA$ at $-20^{\circ} \mathrm{C}$. While this difference of crystal thickness characterized during cooling of ADMF is significant, even taking into account an estimated $10 \%$ incertitude on the PW determined using PEAKFIT Software, this point could be clarified in further experiments using, for instance, polarized light microscopy as a complementary investigation tool.

\subsubsection{Thermal analysis}

The thermal behavior of ADMF was monitored with both the coupled XRDT/ DSC techniques at LURE and in the lab with a DSC-7 calorimeter (Perkin Elmer). Using DSC-7, crystallization was monitored in a broader range of temperatures than with coupled techniques from 60 to $-30{ }^{\circ} \mathrm{C}$ at $|\mathrm{dT} / \mathrm{dt}|=0.1^{\circ} \mathrm{C} \cdot \mathrm{min}^{-1}$ and melting behavior was monitored from -30 to $60{ }^{\circ} \mathrm{C}$ at $\mathrm{dT} / \mathrm{dt}=$ $1^{\circ} \mathrm{C} \cdot \mathrm{min}^{-1}$.

The comparison of structural events recorded by XRDT (Figs. 1A, 1B, 2A and 2B) and the thermal analysis monitored by DSC allows the characterization of the crystallization behavior of ADMF. Figure 3C shows the DSC recording obtained simultaneously with small- and wide-angle XRD experiments (Figs. 1A and 1B) during cooling of $\mathrm{ADMF}$ at $|\mathrm{dT} / \mathrm{dt}|=0.1{ }^{\circ} \mathrm{C} \cdot \mathrm{min}^{-1}$.

The first exothermal event recorded on cooling from $31^{\circ} \mathrm{C}$ corresponds to the formation of the crystalline structure $2 \mathrm{~L}(42.65 \AA)$ characterized by XRD from $29.5^{\circ} \mathrm{C}$. The second exotherm recorded from about 20 to $0{ }^{\circ} \mathrm{C}$ during cooling of ADMF corresponds to crystallization of TG that may be constituted by FA with shorter chains. These TG are incorporated in the bilayered structure formed at higher temperatures. The increase in the amount of TG crystallized is related to the increase in intensity of the XRD line recorded at small angles (Figs. 1A and 2A), corresponding to their longitudinal organization.

Figure 4 shows the DSC recordings obtained in the same conditions using a DSC-7 calorimeter. Both independent DSC recordings display an initial sharp crystallization starting at $\mathrm{T}>30^{\circ} \mathrm{C}$ followed by a broad peak spreading from about 25 to $5^{\circ} \mathrm{C}$. The existence of some minor additional crystallization peaks (four) suspected above from XRD analysis is revealed by the conventional DSC recordings (Fig. 4). 


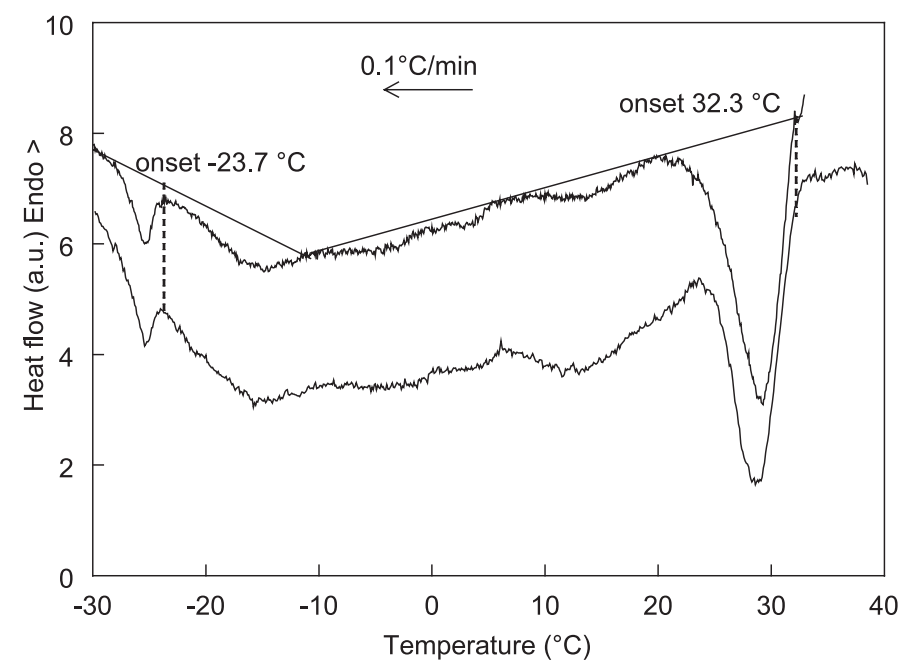

Figure 4. DSC crystallization curves recorded during cooling of anhydrous dromedary milk fat at $0.1^{\circ} \mathrm{C} \cdot \mathrm{min}^{-1}$, using DSC-7.

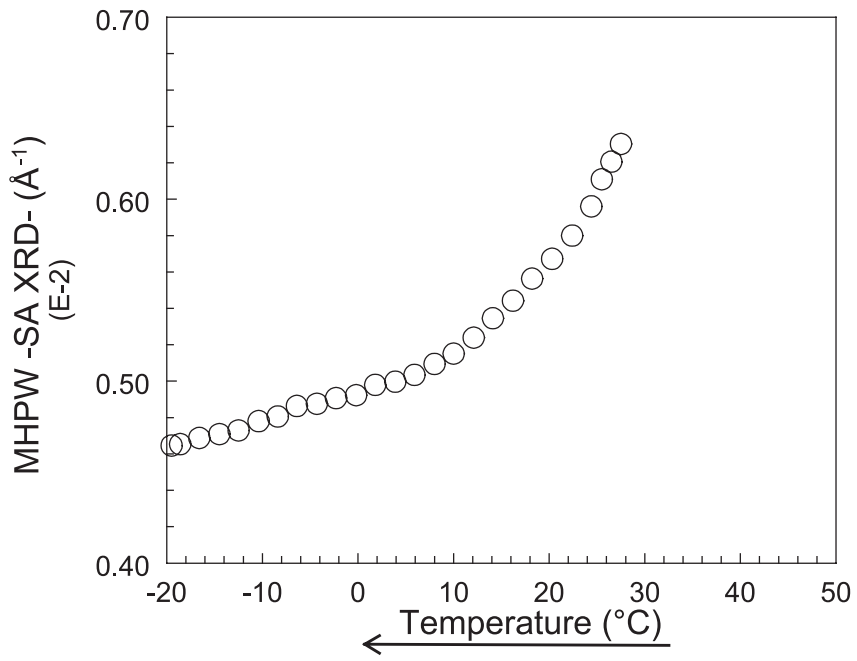

Figure 5. Evolution of the middle-height peak width (MHPW, expressed in $\AA^{-1}$ ) recorded by XRD at small angles (SA), as a function of the temperature, during cooling of anhydrous dromedary milk fat at $0.1^{\circ} \mathrm{C} \cdot \mathrm{min}^{-1}$.

Whichever DSC recording is considered, the onset temperature of crystallization is always higher than that observed by XRD. Large enough domains of crystalline mate- rial are required to get diffraction peaks (note the scattering at small angles of these crystals) (Fig. 1A). The difference in the onset temperatures observed by the two 

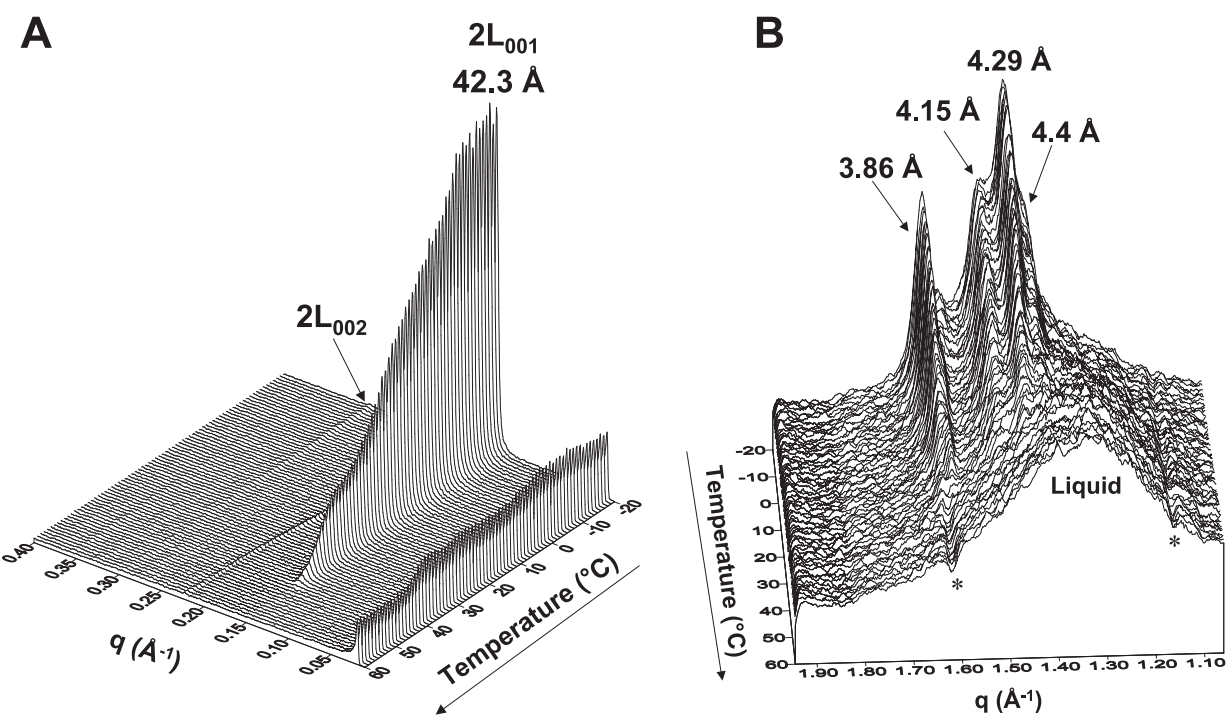

Figure 6. Three-dimensional plots of small- (A) and wide- (B) angle X-ray diffraction patterns recorded as a function of time during heating of anhydrous dromedary milk fat at $1^{\circ} \mathrm{C} \cdot \mathrm{min}^{-1}$ after cooling at $0.1^{\circ} \mathrm{C} \cdot \mathrm{min}^{-1}$. (Asterisk symbols correspond to negative peaks due to the wide-angle detector defects).

DSC techniques is related to the sample holder material (glass or aluminum) as previously discussed [21].

\subsection{Heating of ADMF after slow cooling}

After cooling at $|\mathrm{dT} / \mathrm{dt}|=0.1^{\circ} \mathrm{C} \cdot \mathrm{min}^{-1}$, the ADMF sample was heated at $\mathrm{dT} / \mathrm{dt}=$ $1{ }^{\circ} \mathrm{C} \cdot \mathrm{min}^{-1}$ from $-20{ }^{\circ} \mathrm{C}$ to $60{ }^{\circ} \mathrm{C}$ to study the melting behavior of the crystalline structures formed with a slow cooling rate.

\subsubsection{Structural analysis}

The XRD patterns recorded simultaneously at small and wide angles show the progressive decrease in intensity of the diffraction peaks during the increase in temperature, corresponding to the melting of the crystalline structures formed during cooling (Figs. 6A and 6B). For T $>42{ }^{\circ} \mathrm{C}$ the absence of diffraction peaks at small angles and the recording of the broad peak of scattering observed at wide angles mean that all the TG of ADMF are in their liquid state.

\subsubsection{Intensity evolution}

The evolutions as a function of temperature of maximal intensities of each diffraction peak recorded at both small and wide angles during heating of ADMF were plotted together with DSC recordings (Fig. 7) in order to delimit the domains (ranges) of existence of the crystals.

On heating at $1^{\circ} \mathrm{C} \cdot \mathrm{min}^{-1}$, the decrease in intensity of the long spacing (Fig. 7A) formed on cooling is correlated with the melting of the $\beta$ ' crystals (Fig. 7B).

The evolutions of intensity of the XRD line corresponding to the $2 \mathrm{~L}$ structure can be shared in several temperature-delimited domains. For $-20{ }^{\circ} \mathrm{C} \leq \mathrm{T} \leq-7.5^{\circ} \mathrm{C}$, the line does not show a significant evolution (slope $=$ $-0.52 \% /{ }^{\circ} \mathrm{C}$ ). For $-7^{\circ} \mathrm{C} \leq \mathrm{T} \leq 2{ }^{\circ} \mathrm{C}$, the intensity 


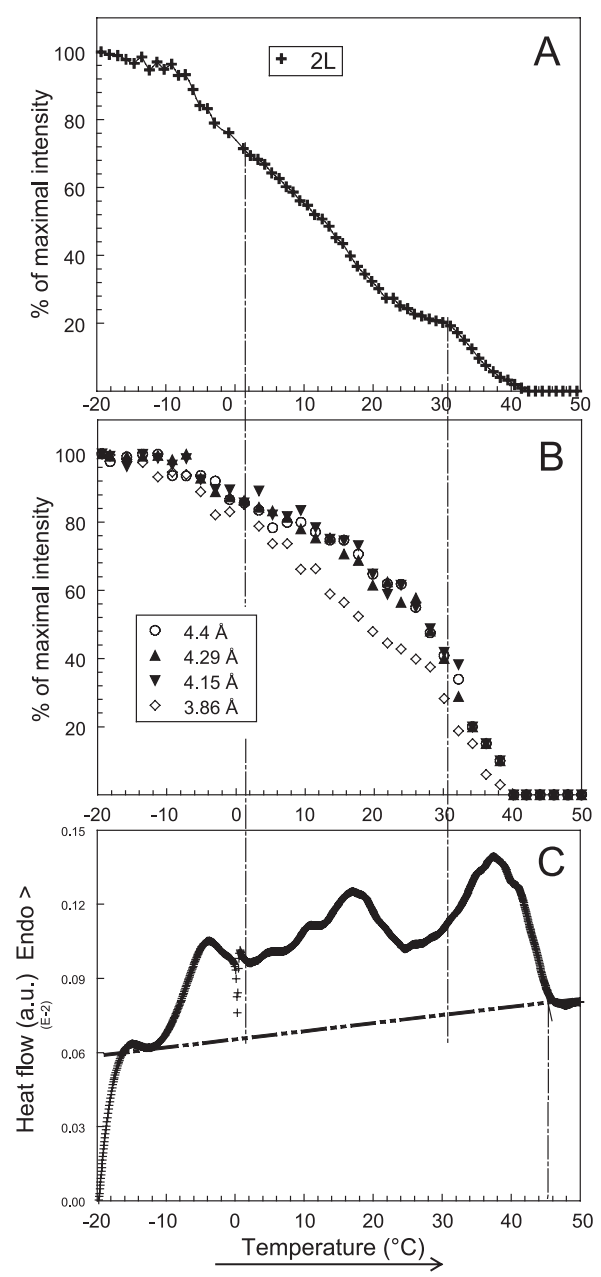

Figure 7. Evolution of the maximal intensities of the diffraction peaks recorded in Figure 6. (A) Evolution of the long spacing, (B) evolution of the short spacings, and (C) DSC melting curve recorded simultaneously to XRD experiments during heating of anhydrous dromedary milk fat at $1^{\circ} \mathrm{C} \cdot \mathrm{min}^{-1}$, following cooling at $0.1^{\circ} \mathrm{C} \cdot \mathrm{min}^{-1}$.

of the $2 \mathrm{~L}$ line strongly decreases (slope $=$ $\left.-2.64 \% /{ }^{\circ} \mathrm{C}\right)$. In the $3{ }^{\circ} \mathrm{C}-30{ }^{\circ} \mathrm{C}$ domain, the line decreases in intensity (from $3{ }^{\circ} \mathrm{C}$ to $25^{\circ} \mathrm{C}$, slope $=-2 \% /{ }^{\circ} \mathrm{C}$ ) then tends to stabilize (from $25{ }^{\circ} \mathrm{C}$ to $30{ }^{\circ} \mathrm{C}$, slope $=-0.8 \% /{ }^{\circ} \mathrm{C}$ ). For $31^{\circ} \mathrm{C} \leq \mathrm{T} \leq 42{ }^{\circ} \mathrm{C}$, the decrease in inten- sity (slope $=-1.7 \% /{ }^{\circ} \mathrm{C}$ ) of the diffraction line associated with the $2 \mathrm{~L}$ structure is correlated with an increase in its thickness (see below). These results show the progressive melting of the TG incorporated in this structure until the final melting of all the TG of ADMF.

The domains of decrease in intensity of the $2 \mathrm{~L}$ line are related to the three main endothermal events recorded simultaneously by DSC (Fig. 7C) (see above).

It is worth noting that, at wide angles, both the overlapping of the four diffraction peaks and the evolution of the broad peak of scattering increase the difficulty of precisely determining their position and intensity as a function of temperature (Fig. 6B). The evolution of the intensity and position of the broad peak of scattering during heating of $\mathrm{ADMF}$ is related to the melting of TG (increase in TG in their liquid state) as a function of the increase in temperature.

The broad peak centered at $\mathrm{q} \sim 1.36 \AA^{-1}$ (4.6 $\AA$ ) corresponds to the average distance between the hydrocarbon chains in the liquid state [13].

\subsubsection{Spacing and peak width evolution}

The evolution vs. temperature of the long spacing calculated from the diffraction peak recorded at small angles is shown in Figure 9A.

The position of the peak corresponding to the 2L structure formed after slow cooling of ADMF was determined for each XRD pattern recorded as a function of temperature during heating of the sample. The thickness of the $2 \mathrm{~L}$ lamellar structure only increases slightly from $42.28 \AA\left(-20^{\circ} \mathrm{C}\right)$ to $42.35 \AA\left(34^{\circ} \mathrm{C}\right)$, meaning that no changes occur in the longitudinal stacking of TG molecules (Fig. 9A). Then, from $34{ }^{\circ} \mathrm{C}$ to its final melting point over $41.5^{\circ} \mathrm{C}$, the thickness of the bilayered structure strongly increases until about $42.68 \AA$ (Fig. 9A). The structural changes that occur from $34{ }^{\circ} \mathrm{C}$ are attributed to progressive and selective melting of the TG molecules of ADMF. 


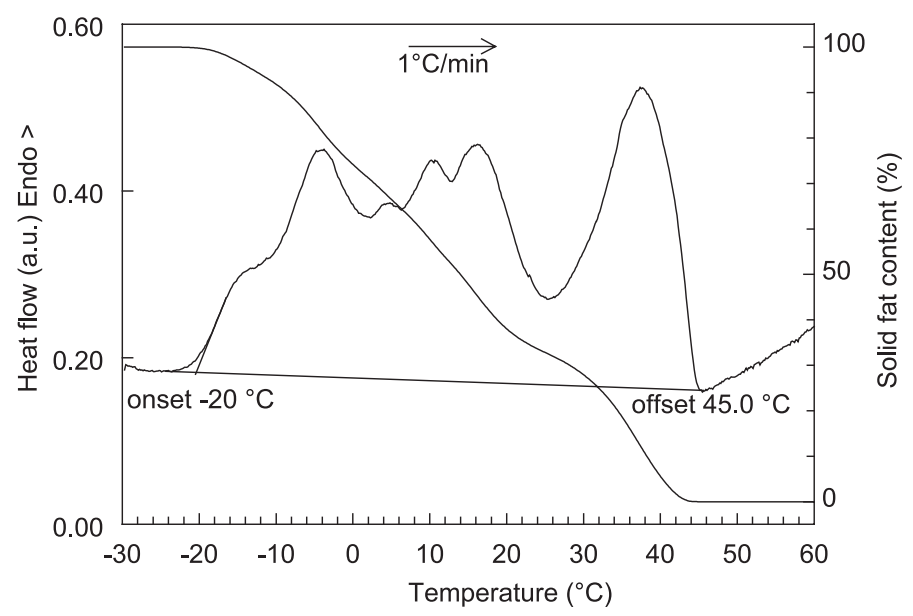

Figure 8. DSC melting curve recorded in the same conditions as for Figure 7, using DSC-7. Integration curve of the DSC recording between onset (about $-20^{\circ} \mathrm{C}$ ) and offset (about $45^{\circ} \mathrm{C}$ ) has been normalized to $100 \%$ in order to provide SFC variation as a function of temperature.

The width of the main XRD peak recorded at small angles was measured at middle-height for each pattern recorded during heating of ADMF. The evolution of the middle-height peak width is presented as a function of temperature (Fig. 9B).

The peak width increases by about $30 \%$ from $-20{ }^{\circ} \mathrm{C}$, (MHPW $\left.=0.004532 \AA^{-1}\right)$ to $33{ }^{\circ} \mathrm{C}\left(\mathrm{MHPW}=0.005943 \AA^{-1}\right)$. Then, the width strongly increases by $49 \%$ until its disappearance above $41.5{ }^{\circ} \mathrm{C}(\mathrm{MHPW}=$ $0.008857 \AA^{-1}$ ).

On heating, the short spacings do not show a significant evolution, meaning that no structural reorganizations between the FA chains occurred. Since the melting process at $1{ }^{\circ} \mathrm{C} \cdot \mathrm{min}^{-1}$ corresponded exactly to the reverse of crystallization during slow cooling, we concluded that: (i) the crystallization at slow cooling was a reversible process, and (ii) the crystalline structures formed by the TG in ADMF during slow cooling are stable polymorphic structures.

\subsubsection{Thermal analysis}

The DSC melting curve recorded simultaneously to XRDT experiments shows the overlapping of several endotherms until the final melting temperature at about $45{ }^{\circ} \mathrm{C}$ (Fig. 7C). The presence of such multiple endotherms was confirmed by DSC-7 recordings obtained in the same conditions $\left(1^{\circ} \mathrm{C} \cdot \mathrm{min}^{-1}\right)$ (Fig. 8). The first endotherms at -20 and $-10{ }^{\circ} \mathrm{C}$ are followed by three smaller endotherms at intermediate temperatures (in the range $0-25^{\circ} \mathrm{C}$ ). The larger one is observed between about 25 and $45^{\circ} \mathrm{C}$. All the endotherms overlap each other, spreading the whole melting process more or less continuously between -20 and $45^{\circ} \mathrm{C}$.

\section{DISCUSSION}

First of all, the small peak observed at $\mathrm{q}=$ $0.2-0.23 \AA^{-1}(\mathrm{~d} \sim 30 \AA)$ in Figures $1 \mathrm{~A}$ and $5 \mathrm{~A}$, the position of which changes as a function of temperature (at $50{ }^{\circ} \mathrm{C}: \mathrm{q}=0.2216 \AA^{-1}$ $(\mathrm{d}=28.35 \AA)$; at $-20{ }^{\circ} \mathrm{C}: \mathrm{q}=0.2057 \AA^{-1}$ $(\mathrm{d}=30.55 \AA))$ and which is found at all the temperatures examined, is attributed hypothetically to the presence of waxy lipids in the extracted fat since more polar lipids would be expected to form a bilayer of much larger period. In this respect, the hypothesis that the small endotherm observed at $-23{ }^{\circ} \mathrm{C}$ on 


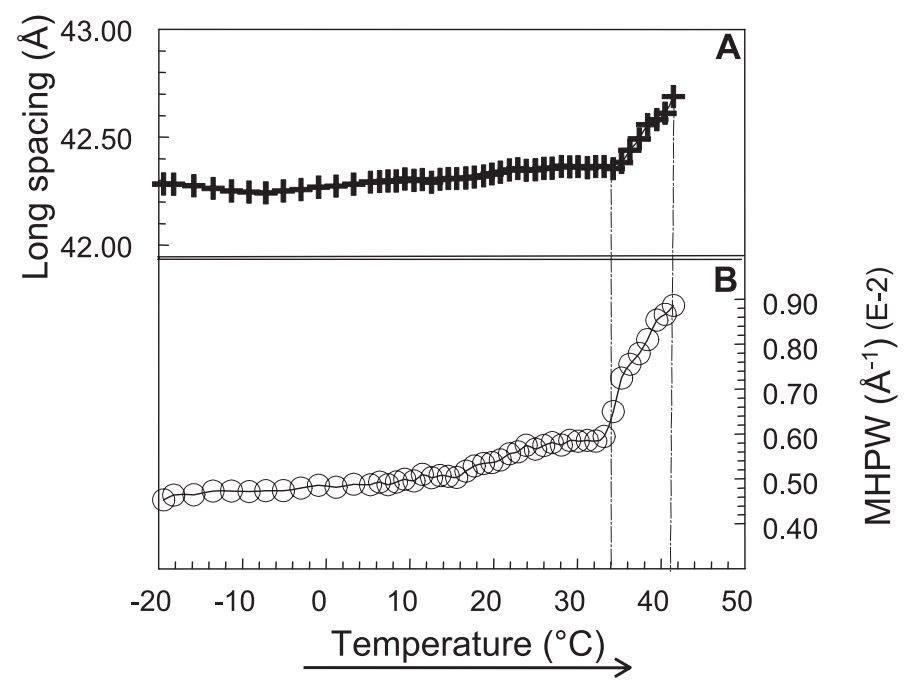

Figure 9. Evolution of the (A) long spacing and (B) middle-height peak width (MHPW, expressed in $\mathrm{A}^{-1}$ ) of the X-ray diffraction peak recorded at small angles (Fig. 6A) during heating of anhydrous dromedary milk fat at $1^{\circ} \mathrm{C} \cdot \mathrm{min}^{-1}$.

cooling would have been due to ice crystallization associated with the presence of polar lipids was also ruled out, the absence of an ice melting peak at about $0{ }^{\circ} \mathrm{C}$ confirming this interpretation.

Both small- and wide-angle XRD results recorded at the slow cooling rate of $|\mathrm{dT} / \mathrm{dt}|=$ $0.1^{\circ} \mathrm{C} \cdot \mathrm{min}^{-1}$ as well as during the following heating at $\mathrm{dT} / \mathrm{dt}=1{ }^{\circ} \mathrm{C} \cdot \mathrm{min}^{-1}$ showed an apparently very simple crystallization process. A single crystalline form corresponding to a $2 \mathrm{~L}$ stacking and a chain packing of $\beta$ ' type is observed on cooling (Figs. 1A and 1B). Upon heating, the melting represents roughly the reverse process of that of crystallization with again the progressive solubilization in the melt of this single crystalline form (Figs. 6A and 6B). The existence of a single species is confirmed by all the temperature analysis of the XRD data obtained during both the crystallization and melting processes (Figs. 2, 3, 7 and 8).
Moreover, from the absence of any new line at small and wide angles during heating there is no evidence of any $\beta^{\prime} \rightarrow \beta$ transition.

One of the main characteristics of dromedary milk fat is that it has very high temperatures for both crystallization onset (between 30 and $32{ }^{\circ} \mathrm{C}$ ) and final melting (about $45{ }^{\circ} \mathrm{C}$ ). This specific characteristic probably makes the dromedary the mammal exhibiting the milk fat with the highest crystallization and melting points. It would be interesting to verify this observation by comparison with the properties of the milk fat of other mammals living in hot areas, with respect to the desert climate and dromedary food and thus to the type of vegetation. ${ }^{1}$

Besides this specific thermal behavior, the broad range over which the crystallization and melting spreads, about $65 \mathrm{~K}$, is also interesting. However, it is difficult to understand

\footnotetext{
${ }^{1}$ Camels have the ability to allow their body temperature to rise as much as $11-14{ }^{\circ} \mathrm{F}$ to reach 104 $106^{\circ} \mathrm{F}$ (about $40-41^{\circ} \mathrm{C}$ ) in the heat of the day. This diminishes the need for evaporative cooling through sweating, thereby reducing water loss. During the cooler night hours, the body temperature returns to about $93{ }^{\circ} \mathrm{F}$. (source: http://www.chaffeezoo.org/zoo/animals/camel.html).
} 
how both crystallization and melting of a single type of crystal could spread over such a range, while being only attributed to a single process. Moreover, the following observations should also be considered: (i) during this broad temperature range of crystallization and melting almost no change is observed in the bilayer period, (ii) the sharpness of the peak associated with the bilayered structure of $42.3 \AA$ is quite surprising, and (iii) its peak width surprisingly decreases as a function of cooling. The observation on cooling of ADMF of a single crystalline structure which corresponds to the formation of mixed crystals incorporating TG molecules with FA chains of different lengths and (un)saturation has already been reported for bovine milk fat [21]. Thus, formation of a single structure as described above is in agreement with previous observations on bovine milk fat, but the sharpening of the small-angle XRD peak observed contrasts with previous results.

In addition, the formation of a single crystalline species is not in agreement with the multiple steps observed on both crystallization or melting DSC recordings during which up to 6 exothermic or endothermic peaks were observed. Moreover, the careful analysis of the X-ray intensity evolutions made in Figures 3A and 7A confirms that both crystallization and melting develop step by step. Thus, these two figures and four independent DSC recordings (Figs. 3C, 4, 7C and 8) demonstrate that the crystallization and melting rates are not constant and depend on the temperature domain considered. Therefore, an alternative analysis of the evolution of the long spacing, intensities and middle-height widths of the small-angle XRD peaks shown in Figure $1 \mathrm{~A}$ and obtained during cooling at $|\mathrm{dT} / \mathrm{dt}|=$ $0.1^{\circ} \mathrm{C} \cdot \mathrm{min}^{-1}$ was undertaken tentatively. The data resulting from this new analysis are shown in Figure 1 insert. In spite of the high resolution of X-ray diffraction, several attempts to fit the small-angle curves using PEAKFIT analysis were not successful at explaining the multiple DSC endotherms and exotherms recorded. However, there is no doubt from this analysis that several types of crystals of similar period coexist.

One question remains: how such crystals develop from the broad FA and TG composition of the dromedary milk fat? Is it possible that changes in the longitudinal organization of TG molecules in well-defined planes are compensated by the formation of different orthorhombic lateral packings? The superimposition of the intensity variations of wide-angle XRD lines plotted as a function of temperature (Figs. 3B and 7B) seems to rule out this hypothesis. However, one has to admit that all types of TG found in ADMF co-crystallize in crystals of similar period. Therefore, an epitaxy phenomenon of the crystals of the second species by those crystallizing first cannot be ruled out.

The change in the solid fat content (SFC) of ADMF has been deduced from DSC melting recording between onset (about $-20^{\circ} \mathrm{C}$ ) and offset (about $45^{\circ} \mathrm{C}$ ) using a simple numerical integration procedure (Fig. 8) not taking into account the enthalpy variation procedure proposed by Lavigne [15]. This SFC variation as a function of temperature has been normalized to $100 \%$ in order to provide useful data for the determination of churning process conditions. The churning temperature conditions of bovine and camel milk fat have already been compared by Rüegg and Farah [31] using DSC melting curves recorded at $5{ }^{\circ} \mathrm{C} \cdot \mathrm{min}^{-1}$. The present study, which was performed at a slow cooling rate $\left(0.1^{\circ} \mathrm{C} \cdot \mathrm{min}^{-1}\right)$, confirms that from room $\mathrm{T}$ (about $20^{\circ} \mathrm{C}$ ), the melting curve of ADMF is shifted by about $5-8{ }^{\circ} \mathrm{C}$ towards higher T for ADMF [15, 31]. Consequently, the churning temperature of ADMF should be increased from the usual T range, about $10-14{ }^{\circ} \mathrm{C}$, to about $20{ }^{\circ} \mathrm{C}$ [31].

The chromatographic analyses of FA from camel and bovine milk fat showed that these two compositions are very different (Tab. I). This difference is not surprising, taking into account both the different pathways of FA biosynthesis and feed of the milch species. 
In dromedary milk fat, the total amount of saturated FA is about $60-65 \%$ and is similar to that found in bovine milk fat [3]. Assuming the distribution of saturated FA on glycerol is similar for both fats, then the mean saturated chain length for $n \geq 12$ increase $\left(\sum \mathrm{x}_{\mathrm{i}} \mathrm{C}_{\mathrm{i}} / \Sigma \mathrm{x}_{\mathrm{i}}\right)$ observed, i.e., from $15.65 \AA$ for bovine to $16.05 \AA$ for dromedary milk fat, is responsible for the temperature increase in thermal properties discussed above. Thus, this chain length increase exactly explains the $2 \mathrm{~L}$ distance increase observed for the $\beta$ ' form of the latter $(42.3 \AA$ instead of $41.5 \AA \Delta=0.8=0.4 \times$ $2 \AA$ ) not taking into account the negligible influence of chain tilt $\left(\Delta_{\text {tilt }} \leq 0.1 \AA\right)$ in Table I. Therefore, it is assumed that the structures of the $\beta$ ' form of both milk fats obtained after cooling at $0.1^{\circ} \mathrm{C} \cdot \mathrm{min}^{-1}$ are similar [21].

The difference in structural behavior between bovine and dromedary fats is striking. The absence of triple chain length period $(3 \mathrm{~L})$ in the small-angle patterns of dromedary fat must be related to the fat composition. Although the amount of oleic acid in both fats is similar, while stearic acid is about twice as much in camel as in bovine milk fat, the monounsaturated TG that presumably also exist in dromedary fat should pack in a $2 \mathrm{~L}$ form. The absence of $3 \mathrm{~L}$ stacking could also be related to the low amount of short FA chains and to the fact that no crystalline segregation of the TG group is observed in dromedary fat. Hence, because of the formation of compound crystals, i.e., crystals containing a range of different $\mathrm{TG}$, one can predict that fractionation of camel milk fat would be difficult. HPLC or GC analysis of the TG composition of dromedary milk fat would be welcome to understand the very specific structural and thermal properties observed.

\section{CONCLUSION}

For the first time, the crystalline structures formed by the TG of ADMF were identified during a slow cooling. The lamellar organization of the TG molecules was characterized and detailed, as well as its thermal stability on heating. Unexpected very simple structural behavior, characterized by XRD at small angles, was associated with complex thermal properties. Coupling of XRDT and DSC experiments was necessary to reveal the complex thermal and structural recordings of ADMF. It has been observed that the lateral packing of TG molecules is loose enough to adapt the wide variety of the FA chains of ADMF and the defects they introduce in the crystalline structure while keeping a perfect longitudinal organization.

The study of the thermal and structural behavior of natural fats is of importance regarding their consequences in the functional and rheological properties of foods, for instance, studies have reported the difficulties of churning dromedary milk fat $[6$, 31] as well as the understanding of lipid metabolism as a function of climate. In this respect, this is not surprising that ADMF likely represents the milk fat with the highest melting and crystallization points because the dromedary has adapted for a long time to the very hot desert climate. Then, dromedary fat displays thermal properties of special interest.

Acknowledgements: W. AMARA is acknowledged for DSC recordings at slow cooling rates using DSC-7. We thank Prof. H. ATTIA (ENIS, Sfax, Tunisia) for pertinent advice and drawing our attention to camel milk fat.

\section{REFERENCES}

[1] Abu-Lehia I.H., Physical and chemical characteristics of camel milk fat and its fractions, Food Chem. 34 (1989) 261-271.

[2] Abu-Tarboush H.M., Comparison of associative growth and proteolytic activity of yoghurt starters in whole milk from camels and bovines, J. Dairy Sci. 79 (1996) 366-371.

[3] Attia H., Kherouatou N., Fakhfakh N., Khorchani T., Trigui N., Dromedary milk fat: biochemical, microscopic and rheological characteristics, J. Food Lipids 7 (2000) 95112. 
[4] Bayoumi S., Studies on composition and rennet coagulation of camel milk, Kiel. Milchwirt. Forschungsber. 42 (1990) 3-8.

[5] Blanton T.N., Barnes C.L., Lelental M., Preparation of silver behenate coatings to provide low- to mid-angle diffraction calibration, J. Appl. Cryst. 33 (2000) 172-173.

[6] Farah Z., Streiff T., Bachmann M.R., Manufacture and characterization of camel milk butter, Milchwissenschaft 44 (1989) 412414.

[7] Guinier A., Théorie et pratique de la radiocristallographie, $3^{\mathrm{e}}$ édn., Dunod, Paris, 1964.

[8] Grabielle-Madelmont C., Perron R., Calorimetric studies on phospholipid-water systems. I. DL-Dipalmitoylphosphatidylcholine (DPPC)-water system, J. Colloid Interface Sci. 95 (1983) 483-493.

[9] Hagemann J.W., Thermal behavior and polymorphism of acylglycerides, in: Garti N., Sato K. (Eds.), Crystallisation and Polymorphism of Fats and Fatty Acids, Marcel Dekker Inc., New York, USA, 1988, pp. 9-95.

[10] Kellens M., Meeussen W., Rikel C., Reynaers H., Time-resolved X-ray diffraction studies of the polymorphic behaviour of tripalmitin using synchrotron radiation, Chem. Phys. Lipids 52 (1990) 79-98.

[11] Keller G., Lavigne F., Forte L., Andrieux K., Dahim M., Loisel C., Ollivon M., Bourgaux C., Lesieur P., DSC and X-Ray diffraction coupling. Specifications and applications, J. Therm. Anal. 51 (1998) 783-791.

[12] Knoess K.H., Le chameau producteur de viande et de lait, Rev. Mond. Zootech. 22 (1977) 39-44.

[13] Larsson K., On the structure of the liquid state of triglycerides, J. Amer. Oil Chem. Soc. 69 (1992) 835-836.

[14] Larsson K., Lipids - Molecular organization, physical functions and technical applications, The Oily Press, Dundee, England, 1994.

[15] Lavigne F., Polymorphisme et transitions de phases des triglycérides. Applications aux propriétés thermiques et structurales de la matière grasse laitière anhydre et de ses fractions. Ph.D. thesis, Univ. Paris VII, Paris XI et ENSIA, 1995.

[16] Lavigne F., Ollivon M., Differential scanning calorimetry and dynamic X-ray diffraction studies of polymorphic transitions of 2oleo-dipalmitin, in: Proceedings of AFCAT 24, Journées Méditerranéennes de Calorimétrie et d'Analyse Thermique, Corte, France, Sept. 1993, pp. 237-241.

[17] Loisel C., Keller G., Lecq G., Bourgaux C., Ollivon M., Phase transition and polymor- phism of cocoa butter, J. Amer. Oil Chem. Soc. 75 (1998) 425-439.

[18] Lopez C., Lesieur P., Keller G., Ollivon M., Thermal and structural behavior of milk fat 1. Unstable species of cream, J. Colloid Interface Sci. 229 (2000) 62-71.

[19] Lopez C., Lavigne F., Lesieur P., Bourgaux C., Ollivon M., Thermal and structural behavior of milk fat. 1. Unstable species of anhydrous milk fat, J. Dairy Sci. 84 (2001) 756766.

[20] Lopez C., Lesieur P., Bourgaux C., Keller G., Ollivon M., Thermal and structural behavior of milk fat. 2. Crystalline forms obtained by slow cooling of cream, J. Colloid Interface Sci. 240 (2001) 150-161.

[21] Lopez C., Lavigne F., Lesieur P., Keller G., Ollivon M., Thermal and structural behavior of anhydrous milk fat. 2. Crystalline forms obtained by slow cooling, J. Dairy Sci. 84 (2001) 2402-2412.

[22] Lopez C., Riaublanc A., Lesieur P., Bourgaux C., Keller G., Ollivon M., Definition of a model fat for crystallization-in-emulsion studies, J. Amer. Oil Chem. Soc. 78 (2001) 1233-1244.

[23] Lopez C., Bourgaux C., Lesieur P., Ollivon M., Crystalline structures formed in cream and anhydrous milk fat at $4{ }^{\circ} \mathrm{C}$, Lait 82 (2002) 317-335.

[24] Lopez C., Bourgaux C., Lesieur P., Bernadou S., Keller G., Ollivon M., Thermal and structural behavior of milk fat. 3. Influence of cooling rate and droplet size on cream crystallization, J. Colloid Interface Sci. 254 (2002) 64-78.

[25] Lopez C., Lavigne F., Lesieur P., Ollivon M., Thermal and structural behavior of anhydrous milk fat. 3. Influence of cooling rate, J. Dairy Sci. (2004) in press.

[26] Mehaia M.A., Fresh soft white cheese from camel milk: composition, yield and sensory evaluation, J. Dairy Sci. 76 (1993) 28452855.

[27] Mohamed M.A., Larsson-Raznikiewicz M., Mohamud M.A., Hard cheese making from camel milk, Milchwissenschaft 45 (1990) 716-718.

[28] Ollivon M., Perron R., Phase transitions and polymorphism of saturated even monoacid triglycerides, in: J. Hollo (Ed.), Fat science, Part A, Elsevier, New York, USA, 1985, pp. 107-116.

[29] Ollivon M., Perron R., Propriétés physiques des corps gras, in: Karleskind A., Wolff J.P., Guttmann J.F. (Eds.), Manuel des Corps Gras, Lavoisier, Paris, 1992, pp. 433-442. 
[30] Orlov V.K., Servetnik-Chalaya G.K., Some physical and chemical characteristics of fat and fatty acid composition of lipids of camel milk, Voprosy Pitaniya 5 (1981) 67-69.

[31] Rüegg M.W., Farah Z., Melting curves of camel milk fat, Milchwissenschaft 46 (1991) 361-362.

[32] Sato K., Polymorphism of pure triacylglycerols and natural fats, in: Advances in Applied
Lipid Research, Vol. 2, JAI Press Inc., 1996, pp. 213-268.

[33] Sawaya W.N., Khalil J.K., Al-Shalhat A., Al-Mohammed H., Chemical composition and nutrition quality of camel milk, J. Food Sci. 49 (1984) 744-747.

[34] Small D.M., The physical chemistry of lipids. From alkanes to phospholipids, in: Hanahan D.J. (Ed.), Handbook of Lipid Research, Plenum Press, New York, USA, 1986, pp. 347-382. 